\title{
Fatty acids and epithelial permeability: effect of conjugated linoleic acid in Caco-2 cells
}

\author{
H M Roche, A M Terres, I B Black, M J Gibney, D Kelleher
}

\begin{abstract}
Conjugated linoleic acid (CLA) is a collective term referring to the positional and geometric isomers of linoleic acid. This novel fatty acid has been shown to have a number of beneficial actions, including immunomodulatory, anticarcinogenic, and antiatherogenic effects. Tight junctions of epithelial cells determine epithelial membrane integrity and selective paracellular permeability to ions and macromolecules. Occludin and ZO-1 are integral structural components of the tight junction, which are involved in the biogenesis and functional integrity of the epithelial monolayer. This study investigated the effects of two isomers of CLA (cis-9 and trans-10 isomers) on Caco-2 cell transepithelial resistance (TER) development, paracellular epithelial permeability, and occludin and ZO-1 expression. Caco-2 cells were grown in media supplemented with $0.05 \mathrm{mM}$ linoleic acid, cis-9 CLA, or trans-10 CLA for 21 days. The trans-10 CLA isomer delayed Caco-2 cell TER development, which is an in vitro measure of epithelial cell integrity, and increased paracellular epithelial permeability. Immunofluorescent staining of Caco-2 cell epithelial monolayers grown in media supplemented trans-10 CLA showed that the trans-10 CLA isomer altered distribution of occludin and ZO-1. The trans-10 CLA isomer delayed the acquisition of transepithelial resistance and altered the cellular distribution of occludin, which have important implications in relation to epithelial permeability. (Gut 2001;48:797-802)
\end{abstract}

Keywords: conjugated linoleic acid; occludin; ZO-1; tight junction; epithelial permeability; Caco- 2 cells

Department of Clinical Medicine, Trinity College, Dublin, Ireland

H M Roche

A $M$ Terres

I B Black

M J Gibney

D Kelleher

Correspondence to: H M Roche, Department of Clinical Medicine, Trinity Centre for Health Sciences, St James's Hospital, James's Street, Dublin 8, Ireland. hmroche@tcd.ie

Accepted for publication 5 December 2000

for the different geometric isomers. CLA is the product of rumen fermentation, therefore it is normally found as a minor constituent of the lipid fraction of meat, milk, and dairy products. ${ }^{2}$ It is only in the past five years that the potential effects of CLA have been realised, whereby it has been shown that CLA has immunomodulatory, ${ }^{34}$ anticarcinogenic, ${ }^{5}$ and antiatherogenic effects. ${ }^{6}$

Despite the fact that fatty acids play an integral structural and functional role in the phospholipid bilayer of the cell membrane, there has been little investigation of the effects of fatty acid composition on occludin expression and tight junction permeability. Tight junctions of epithelial cells determine epithelial membrane integrity and selective paracellular permeability to ions and macromolecules. Occludin is an integral structural component of the tight junction; it is a transmembrane protein which forms linear protein polymers at the apicallateral membrane of the cell. ${ }^{8}$ The extracellular domain of occludin interacts with occludin molecules of adjacent cells to form intercellular tight junctions. ${ }^{9}$ Occludin size varies between 62 and $82 \mathrm{kDa}$, depending on the degree of phosphorylation. ${ }^{10}$ Phosphorylation of occludin is a key step in tight junction assembly and occurs on the serine threonine residues. The degree of phosphorylation determines the functionality and localisation of occludin in the cell. The less phosphorylated nascent forms of occludin are found in the basolateral membrane, cytosol, and tight junction. The more phosphorylated high molecular weight forms of occludin, which are the functional forms of occludin, are concentrated exclusively in the tight junction. ${ }^{11}$

The other intracellular components of the tight junction, including $\mathrm{ZO}-1, \mathrm{ZO}-2, \mathrm{ZO}-3$, cingulin, $7 \mathrm{H} 6$, claudin 1 , and claudin 2 , have both a structural and functional role in the development and integrity of the tight junction. ${ }^{12} \mathrm{ZO}-1$ binds directly to the $\mathrm{COOH}-$ terminal cytoplasmic domain of occludin and forms a heterodimeric complex with $\mathrm{ZO}-2$ and ZO-3 (p130). ${ }^{13} \mathrm{ZO}-1, \mathrm{ZO}-2$, and ZO-3 belong to the membrane associated guanylate kinase family of proteins which share several conserved motifs, including an $\mathrm{SH} 3$ domain, guanylate kinase domain, and PDZ domain(s) ${ }^{14}$ It is proposed that they function to couple extracellular signalling pathways to the cytoskeleton but the full nature of these effects is unknown. ${ }^{15}$ It has been suggested that ZO-1 may be involved in the biogenesis of tight junctions as the $\mathrm{COOH}-$ terminal domain of occludin contains a $\mathrm{ZO}-1$ binding site which may target occludin to tight junctions. ${ }^{13}$

The integrity of polarised epithelial cell monolayers can be assessed by measuring
Abbreviations used in this paper: CLA, conjugated linoleic acid; LA, linoleic acid; GLA, gamma linolenic acid; ALA, alpha linolenic acid; EPA, eicosapentaenoic acid; TER, transepithelial electrical resistance; PLC, phospholipase C; PKC, phosphokinase C. 
transepithelial electrical resistance (TER), an in vitro measure of the tightness between epithelial cells. It has been demonstrated that TER is directly related to the amount of occludin expressed in polarised epithelial cell monolayers. ${ }^{16}$ It has also been shown that the fatty acid composition of the cell culture medium affects tight junction permeability, as assessed using TER, and occludin expression. Jiang and colleagues ${ }^{17}$ investigated the effect of a range of fatty acids (oleic acid (C18:1 n-9), LA (C18:2 n-6), gamma linolenic (GLA; C18:3 n-6), alpha linolenic (ALA; C18:3 n-3), arachidonic acid (C20:4 n-6), eicosatrienoic acid (C20:3 n-3), and eicosapentaenoic acid (EPA; C20:5 n-3)) on tight junction permeability and occludin expression in human vascular endothelial cells (ECV304). It was demonstrated that acute exposure ( $<24$ hours) to GLA, ALA, and EPA significantly increased TER whereas LA significantly reduced TER of ECV304 cells. These changes in TER were reciprocally related to alterations in paracellular permeability which was significantly reduced by GLA and EPA, and significantly increased by LA. Furthermore, the study showed that occludin expression was increased by GLA, ALA, and EPA and significantly reduced by LA.

Clearly fatty acids have the ability to modulate occludin expression and tight junction permeability in epithelial cells. The Caco- 2 cell line, which is derived from human colonic carcinoma, was used in this study because it differentiates in culture into enterocytes and it is a well established model of the human intestinal epithelium. ${ }^{18}$ Monolayers grown on permeable supports have well developed microvilli and express surface markers and tight junctions characteristic of the epithelial cell monolayer of the intestinal villus. The objective of this study was to investigate the effects of two isomers of CLA (cis-9 and trans-10 isomers) on tight junction development, epithelial permeability, and occludin expression in Caco- 2 cells.

\section{Methods}

EPITHELIAL CELL CULTURES

The epithelial cell line Caco-2, obtained from the European Collection of Animal Cell Cultures, was used for the study. Caco- 2 cells were grown in Dulbecco's MEM (DMEM)nutrient mix medium (GibcoBRL, Grand Island, New York, USA), supplemented with $10 \%$ fetal calf serum (GibcoBRL), 1\% sodium pyruvate, and $0.1 \%$ gentamycin. They were incubated in flasks at $37^{\circ} \mathrm{C}$ in a humidified atmosphere of $5 \% \mathrm{CO}_{2}$ and split using a trypsin-EDTA solution (GibcoBRL). The cells were seeded on semi permeable transparent polyethylene terephthalate tracketched support membranes (area $0.9 \mathrm{~cm}^{2}$; pore diameter 0.40 $\mu \mathrm{m}$; pore density $1.6 \times 10^{6}$; Falcon, New Jersey, USA). The cells were seeded at a concentration of $1.3-1.5 \times 10^{5}$ cells $/ \mathrm{ml}$. Cell passages used were between 13 and 15. Cells were grown for 14 and 21 days in media only (controls) or in media supplemented with $0.05 \mathrm{mM}$ LA (Sigma, UK), $0.05 \mathrm{mM}$ trans-10 CLA (trans-10 CLA), or $0.05 \mathrm{mM}$ cis-9 CLA (cis-9 CLA). The trans-10 (10-trans, 12-cis, 98.8\% purity) and cis-9 (9-cis, 11-trans, 93.8\% purity) CLA isomers were kindly supplied by Unilever Research (Colworth, UK).

TER ANALYSIS

TER of the Caco- 2 epithelial cell monolayers was measured using an EVOM epithelial voltohmmeter and STX2 electrode (World Precision Instruments, Sarasota, Florida, USA) at 48 hour intervals.

TRANSLOCATION ASSAY: PARACELLULAR AND INTRACELLULAR MONOLAYER PERMEABILITY The permeability of the Caco- 2 cell monolayers following different fatty acid treatments was measured using two radioactive marker molecules, $\left[{ }^{3} \mathrm{H}\right]$ proprananol (Amersham), a lipophilic intracellular marker, and $\left[{ }^{14} \mathrm{C}\right]$ mannitol (Amersham, Buckinghamshire, UK), an intercellular marker. Epithelial cell monolayer permeability to $\left[{ }^{3} \mathrm{H}\right]$ proprananol and $\left[{ }^{14} \mathrm{C}\right]$ mannitol was examined at 14 and 21 days after seeding of cells cultured in control media (without fatty acids) and cells cultured in media supplemented with $0.05 \mathrm{mM}$ LA, trans10 CLA, and cis-9 CLA, as previously described. ${ }^{19}$ The apparent permeability coefficient $\left(\mathrm{P}_{\text {app }}\right)$ was calculated according to the equation $\quad \mathrm{P}_{\text {app }} \quad(\mathrm{cm} \times \mathrm{s})=(\mathrm{d} Q / \mathrm{d} t(\mathrm{~s}) \times \mathrm{V}) /$ $\mathrm{A}\left(\mathrm{cm}^{2}\right) \times \mathrm{Co}$, where $\mathrm{d} Q / \mathrm{d} t$ is the slope of the cumulative fraction absorbed (DPMs) versus time (in seconds), $\mathrm{V}$ is the volume of the receiver compartment $\left(\mathrm{cm}^{3}\right), \mathrm{A}$ is the area of the filter $\left(\mathrm{cm}^{2}\right)$, and Co is the initial DPMs added to the filter.

MTS PROLIFERATION ASSAY

The effect of $0.05 \mathrm{mM}$ LA, cis-9 CLA, and trans-10 CLA on Caco-2 cell proliferation was investigated using the Cell Titer 96 Aqueous Non-Radioactive Cell Proliferation Assay (Promega, Wisconsin, USA). The manufacturer's protocol was followed but briefly, cells receiving each fatty acid treatment were seeded in 96 well microtitre plates (Falcon) at a density of $10^{5}$ cells/well and grown for 24 hours. MTS/PMS solution $(20 \mu \mathrm{l})$ was added to each well and cells were incubated for four hours at $37^{\circ} \mathrm{C}$ and absorbance read at $490 \mathrm{~nm}$.

\section{IMMUNOFLUORESCENT STAINING}

Caco- 2 cells were grown for 14 and 21 days in control and supplemented media. The media was removed and the monolayers were washed twice in phosphate buffered saline. Immunostaining was performed as previously described. ${ }^{11}$ Briefly, cells were fixed in ice cold methanol for five minutes at $-20^{\circ} \mathrm{C}$, allowed to air dry for three hours, and stored at $-20^{\circ} \mathrm{C}$. The monolayers were rehydrated in blocking solution (3\% skimmed milk powder in TweenTris buffer (50 mM Tris, $150 \mathrm{mM} \mathrm{NaCl}$, $0.05 \%$ Tween 20)) followed by incubation with anti-occludin (Zymed Laboratories Inc., California, USA) or anti-ZO-1 (Zymed Laboratories Inc.) rabbit polyclonal antibodies. Cells were washed and incubated with fluorescein isothiocynate anti-rabbit secondary antibody. After washing the filter, the monolayer of cells 


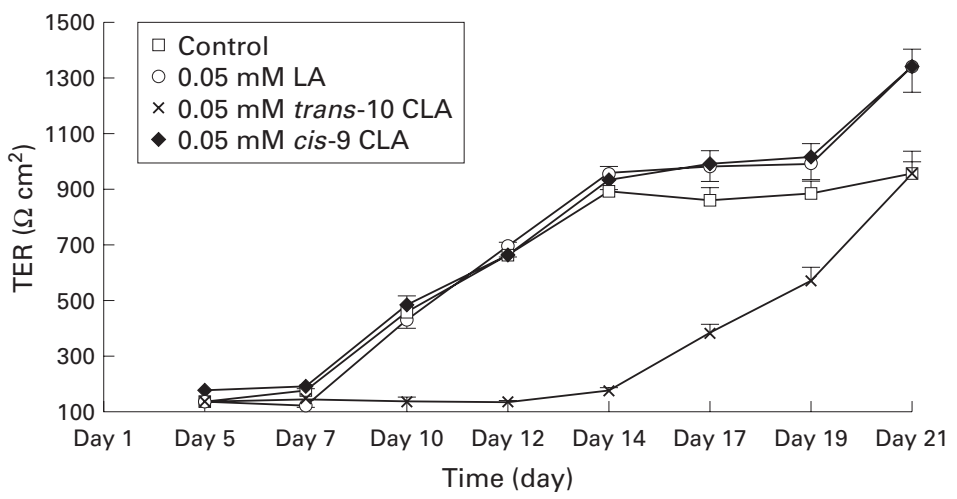

Figure 1 Transenodothelial cell resistance (TER) of cells grown in media supplemented with linoleic acid (LA), trans-10 conjugated linoleic acid (CLA), and cis-9 CLA (0.05

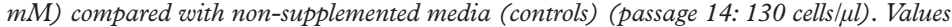
are mean (SEM) TER values of three wells per fatty acid treatment.

were mounted on glass slides in Dako fluorescent mounting medium (Dako, Glostrup, Denmark) for microscopic examination.

STATISTICAL ANALYSIS

Results are expressed as mean (SEM). Statistical analysis was performed using the Apple Macintosh compatible statistical package Data Desk 4.1 (Data Descriptions Inc., New York, USA). One way analysis of variance was used to identify significant differences between fatty acid treatments.

\section{Results}

TRANS-10 CLA ISOMER EFFECTS ON TER

TER values of Caco-2 cells supplemented with $0.05 \mathrm{mM}$ LA, trans-10 CLA, and cis-9 CLA are presented in fig 1. The trans-10 CLA isomer was associated with marked inhibition of TER up to day 14 compared with cells supplemented with LA or cis-9 CLA, or control cells. By day 21 cells supplemented with trans -10 CLA had achieved the same level of TER as cells supplemented with LA or cis-9 CLA, or control cells.

TRANS-10 CLA ISOMER INCREASED PARACELLULAR PERMEABILITY OF CACO-2 CELL EPITHELIAL

MONOLAYERS

TER measurements give an indication of the ionic permeability of tight junctions but can

\section{$\left[{ }^{14} \mathrm{C}\right]$ Mannitol}

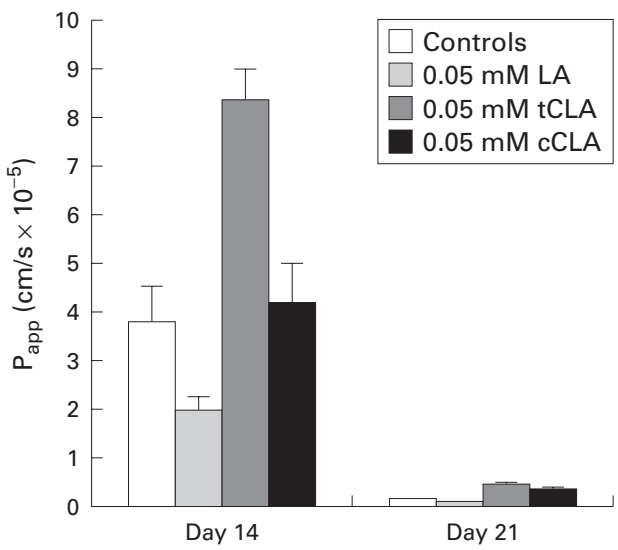

Table 1 MTS proliferation assay: effect of linoleic acid (LA), trans-10 conjugated linoleic acid (CLA), and cis-9 CLA $(0.05 \mathrm{mM})$ (passage 15: 490 cells/ $/ \mathrm{l}$ )

\begin{tabular}{ll}
\hline Treatment & Absorbance \\
\hline Control & $0.929(0.831-1.027)$ \\
$0.05 \mathrm{mM}$ LA & $0.809(0.711-0.907)$ \\
$0.05 \mathrm{mM}$ trans-10 CLA & $0.762(0.710-0.814)$ \\
$0.05 \mathrm{mM}$ cis-9 CLA & $0.888(0.774-1.000)$ \\
\hline
\end{tabular}

Values are mean ( $95 \%$ confidence interval) of three wells per fatty acid treatment.

also reflect changes in membrane conductance. $^{20}$ Therefore, the permeability of cell membranes to paracellular and intracellular markers of flux, $\left[{ }^{14} \mathrm{C}\right]$ mannitol and $\left[{ }^{3} \mathrm{H}\right]$ proprananol, respectively, following different fatty acid treatments is presented in fig 2 . At day 14 there was significantly greater transfer of $\left[{ }^{14} \mathrm{C}\right]$ mannitol across the epithelial monolayers of confluent cells supplemented with trans10 CLA compared with control cells and cells supplemented with LA and cis-9 CLA. At day 21 there was no significant difference in paracellular flux of $\left[{ }^{14} \mathrm{C}\right]$ mannitol between fatty acid treatments. There was no significant difference in intracellular flux of $\left[{ }^{3} \mathrm{H}\right]$ proprananol across the confluent epithelial cell monolayers between fatty acid treatments on either day 14 or day 21 .

FATTY ACID COMPOSITION HAD NO EFFECT ON CELLULAR PROLIFERATION

Results of the MTS proliferation assay of Caco- 2 cells supplemented with $0.05 \mathrm{mM}$ LA, cis-9 CLA, and trans-10 CLA are presented in table 1 . Analysis of variance demonstrated that while the mean absorbance of the cells treated with trans-10 CLA was lower than control cells, this difference was not significant.

TRANS-10 CLA ISOMER AFFECTS OCCLUDIN AND ZO-1 EXPRESSION

The effect of the different fatty acids on occludin and ZO-1 expression in Caco-2 cell epithelial monolayers was analysed by immunofluorescent staining. At day 14, cells cultured in media supplemented with LA and cis-9 CLA had a normal morphology and occludin was

$\left[{ }^{3} \mathrm{H}\right]$ Proprananol

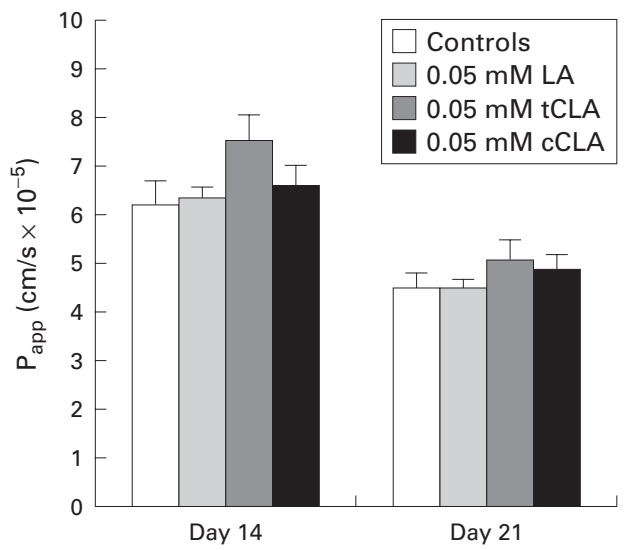

Figure 2 Mean transfer (DPM/hour) of $\left[{ }^{4} \mathrm{Cl}\right.$ mannitol and $\left.{ }^{3} \mathrm{H}\right]$ proprananol of control cells and cells supplemented with $0.05 \mathrm{mM}$ linoleic acid (LA), trans-10 conjugated linoleic acid (tCLA), and cis-9 CLA (cCLA) for day 14 and day 21 (passage 13: 200 cells/ $\mu l$ ). Values are mean (SEM) of three wells per fatty acid treatment. 

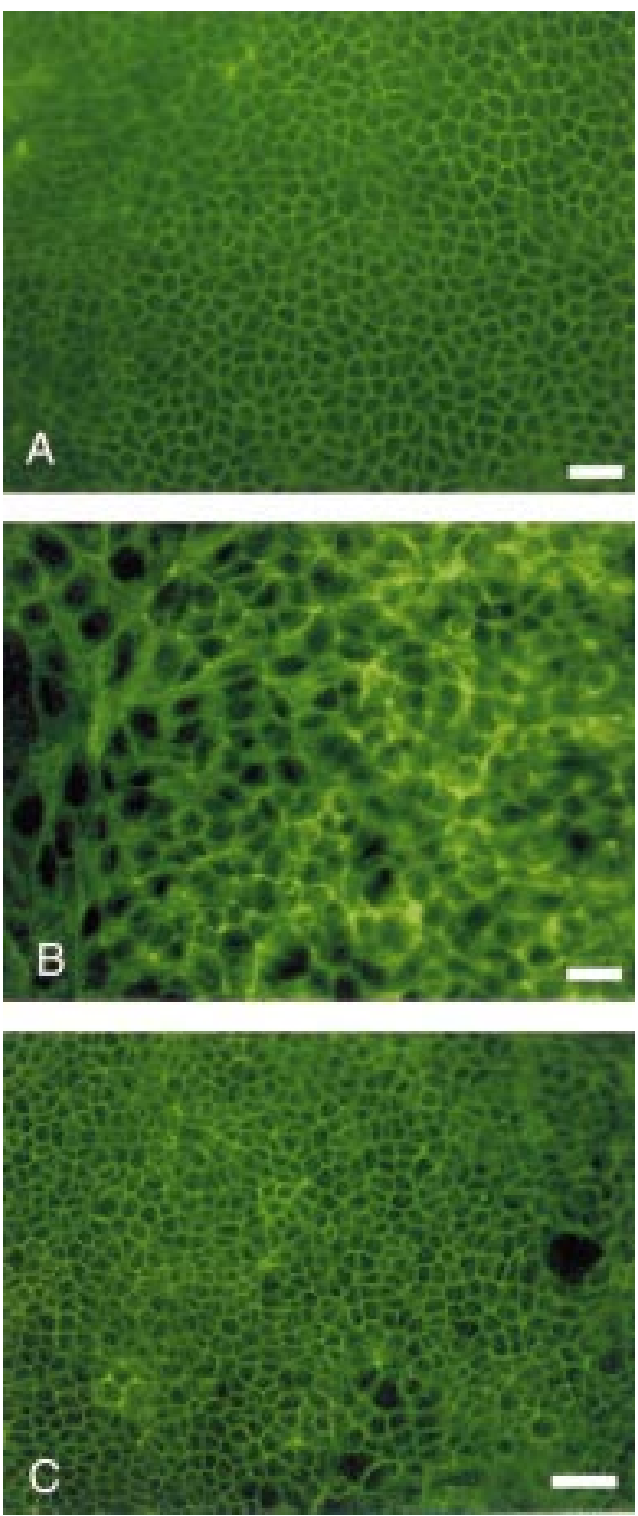

Figure 3 Antioccludin immunofluorescent staining of Caco-2 cell monolayers grown in media supplemented with $0.05 \mathrm{mM}$ linoleic acid $(L A)(A)$, trans-10 conjugated linoleic acid (CLA) (B), and cis-9 CLA (C) for 14 days. Bar $40 \mu \mathrm{m}$.

present in the plasma membrane of cells only (fig 3). However, monolayers of cells cultured in media supplemented with trans-10 CLA isomer had an abnormal localisation and cellular distribution of occludin. At greater magnification (fig 4) it was observed that occludin had a granular appearance and was present in the cytosol of cells cultured in media supplemented with trans-10 CLA. Occludin was exclusively located in the membrane of cells cultured in media supplemented with LA and cis-9 CLA. At day 21, occludin was more closely associated with the membrane but still had a granular appearance and its membranous localisation was not as defined as that shown by cells supplemented with cis-9 CLA and LA (fig 5). The cellular distribution of $\mathrm{ZO}-1$ is shown in fig 6 . ZO- 1 was localised in the plasma membrane of all cells, irrespective of fatty acid treatment. However, membranes of cells supplemented with $0.05 \mathrm{mM}$ trans -10
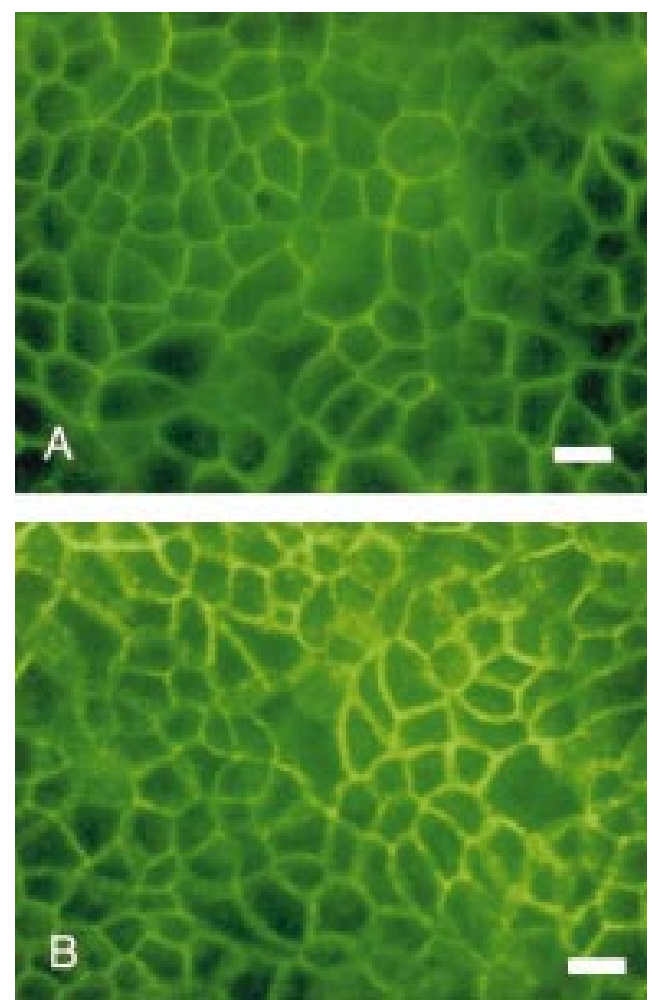

Figure 4 Antioccludin immunofluorescent staining of Caco-2 cell monolayers grown in media supplemented with $0.05 \mathrm{mM}$ linoleic acid $(L A)(A)$ and trans-10 conjugated linoleic acid (CLA) (B) for 14 days. Bar $100 \mu \mathrm{m}$
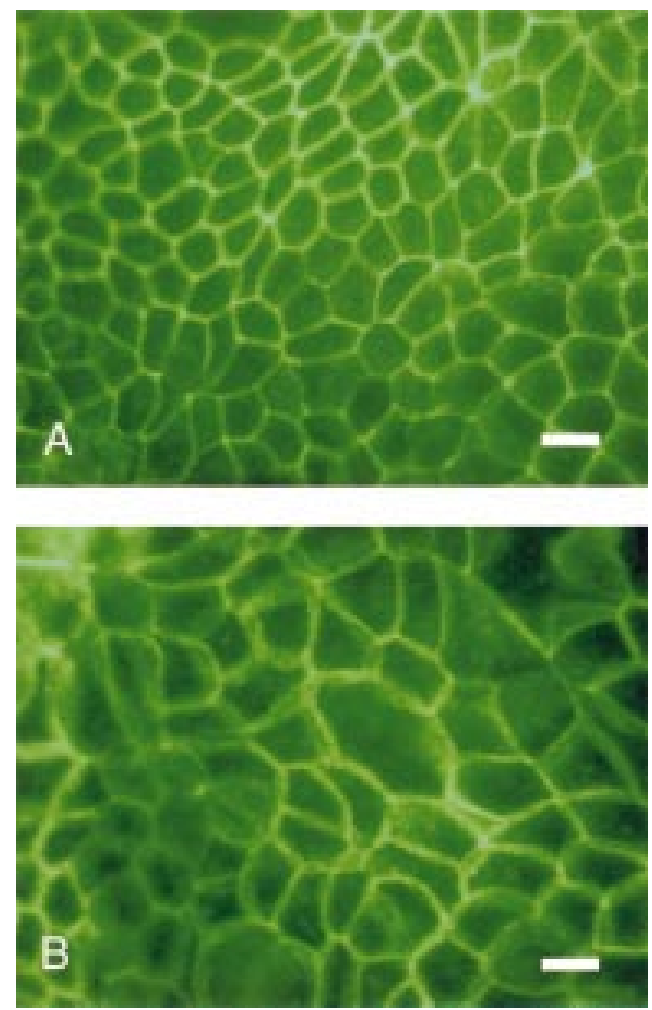

Figure 5 Antioccludin immunofluorescent staining of Caco-2 cell monolayers grown in media supplemented with $0.05 \mathrm{mM}$ linoleic acid $(L A)(A)$ and trans-10 conjugated linoleic acid (CLA) (B) for 21 days. Bar $100 \mu \mathrm{m}$

CLA for 14 days were associated with marked ruffling, an effect which disappeared at 21 days. 

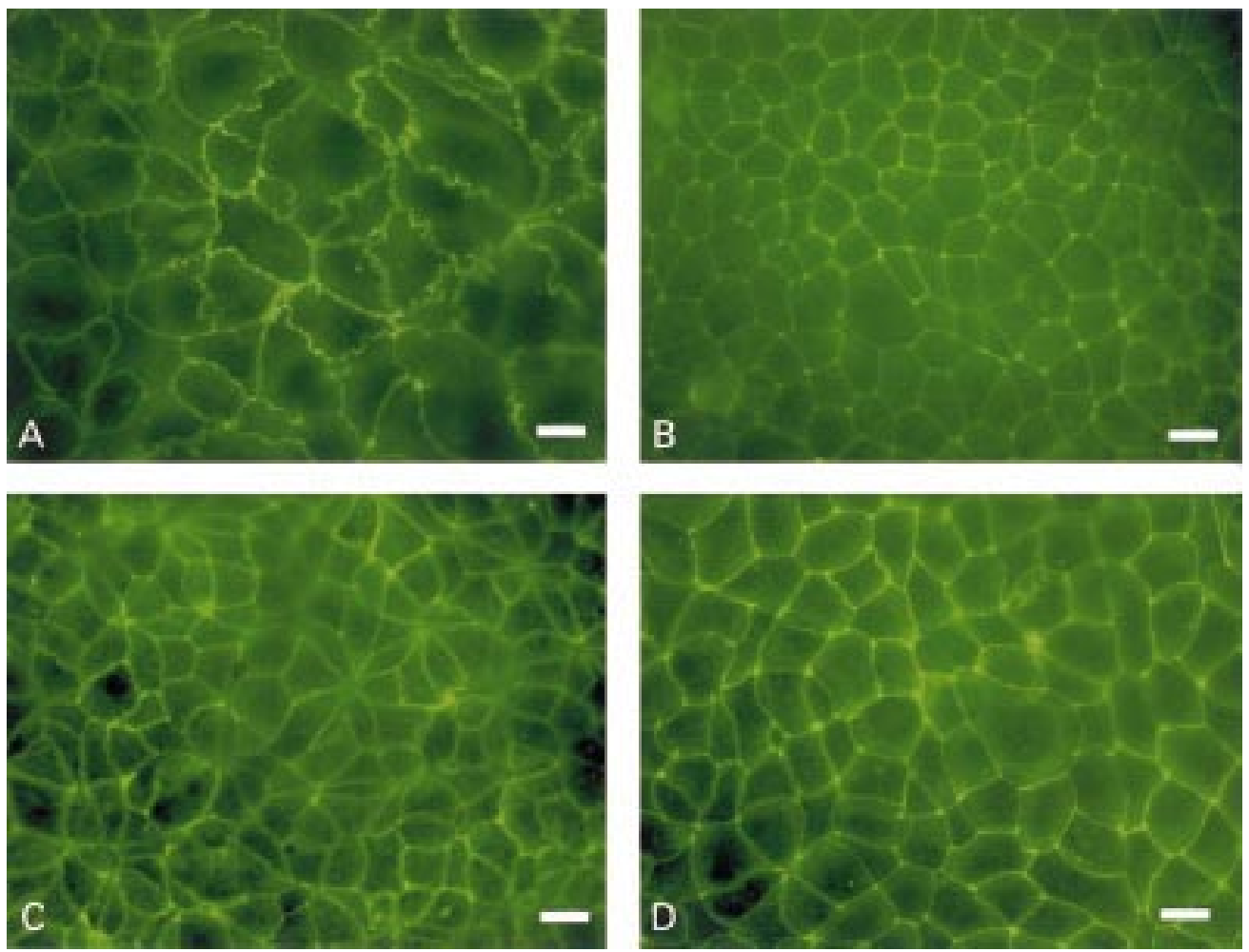

Figure 6 Anti-ZO-1 immunofluorescent staining of Caco-2 cell monolayers grown in media supplemented with $0.05 \mathrm{mM}$ trans-10 conjugated linoleic acid $(C L A)(A, B)$ and cis-9 CLA $(C, D)$ for 14 and 21 days, respectively. Bar $100 \mu m$

\section{Discussion}

The trans-10 isomer of CLA altered the distribution of two tight junction associated proteins, occludin and ZO-1, in the Caco-2 cell model. Supplementation of the culture medium with the trans-10 isomer of CLA also delayed the increase in TER of the Caco- 2 cell epithelial monolayer and was associated with significantly greater paracellular permeability to $\left[{ }^{14} \mathrm{C}\right]$ mannitol. There was no significant effect of the trans-10 CLA isomer on cellular proliferation. Immunofluorescent analysis of occludin expression showed an abnormal distribution of occludin in cells cultured in media supplemented with trans-10 CLA compared with the well defined localisation of occludin in membranes of cells supplemented with LA or cis-9 CLA. Furthermore, there were granules of occludin present in the cytosol of cells cultured in media supplemented with trans-10 CLA. Immunofluorescent staining for ZO-1 showed that trans-10 CLA did not inhibit localisation of ZO-1 in the membrane. Nevertheless, membranes of cells treated with trans-10 CLA had a "ruffled" appearance. The effects of trans-10 CLA on TER, paracellular permeability, occludin, and ZO-1 were obvious after 14 days of supplementation; by day 21 cells had reverted to a near normal state.

As fatty acids are the major constituents of the phospholipid bilayer of the epithelial cell membrane it not surprising that they can modulate adhesion molecule expression and affect epithelial cell permeability. Occludin is an essential component of the tight junction where it determines epithelial membrane integrity and selective paracellular permeability to ions and macromolecules. ${ }^{8} \mathrm{ZO}-1$ is intracellularly associated with the tight junction and is believed to play an important role in their functional regulation. ${ }^{13}$ However, there has been little investigation of the effect of fatty acid composition on tight junction permeability and occludin expression. Jiang and colleagues ${ }^{17}$ recently demonstrated that acute exposure $(1-100 \mu \mathrm{M})$ to GLA (C18:3 n-6) significantly increased TER and occludin expression in human vascular endothelial cells (ECV304) in a dose dependant fashion compared with LA (C18:2 n-6). We have shown that trans-10 CLA affected Caco-2 cell tight junction permeability and both occludin and ZO-1 distribution. Enhanced permeability of the intestinal epithelium by trans-10 CLA may or may not be beneficial, depending on the clinical situation. Increased tight junction permeability could promote intestinal absorption. Conversely, downregulation of tight junction function could have adverse effects, promoting cancer cell invasion and metastasis. Further research is required to determine the clinical implications of trans-10 CLA on epithelial cell permeability.

The molecular basis of the effects shown in this study are difficult to explain but a number of possibilities exist. The trans-10 CLA isomer could have altered the fatty acid composition of the cellular membrane lipid bilayer of Caco-2 cells which in turn could alter the conformation and/or activity of occludin. However, to date, there is no information on the effect of fatty acids on Caco-2 cell membrane fatty acid and protein interactions. In light of the transient nature of the effects of trans-10 CLA, 
it is possible that trans-10 CLA inhibited maturation of occludin. At day 14 the presence of the trans-10 CLA isomer was associated with lower amounts of occludin in the membrane and the presence of occludin in the cytosol of the cell. Occludin migrates on sodium dodecyl sulphate polyacrylamide gel electrophoresis as a series of bands between 62 and $82 \mathrm{kDa}$, depending on the degree of phosphorylation. ${ }^{10}$ Phosphorylation of occludin is a key step in tight junction assembly which in turn affects the localisation of occludin in the cell. In MDCK cells the less phosphorylated low molecular weight forms of occludin are found in the basolateral membrane and cytosol whereas the more phosphorylated high molecular weight forms are concentrated exclusively in the tight junction. ${ }^{10}$ The high molecular weight forms of occludin are the functional forms of occludin which participate in the formation of the tight junction barrier. ${ }^{11}$ In our cell system, the trans-10 isomer may have inhibited phosphorylation of occludin. This hypothesis is supported by immunofluorescent staining which showed the preponderance of occludin in the cytosol which was probably a nascent form of occludin.

To inhibit phosphorylation of occludin, the trans-10 isomer must have interfered with one of the signalling pathways that regulate tight junction biogenesis. Lindmark and colleagues ${ }^{21}$ completed an elegant series of experiments which demonstrated that medium chain fatty acids (C10:0 and C12:0) activated the phospholipase $\mathrm{C}$ (PLC) dependent $\mathrm{IP}_{3} / \mathrm{DAG}$ signalling pathway thereby modulating occludin expression and tight junction permeability. The study showed that these effects were complex whereby effectors of this pathway, phosphokinase $\mathrm{C}$ (PKC) and $\mathrm{Ca}^{2+}$, had divergent effects on the biogenesis of occludin and tight junction permeability. While PKC activation induced PKC mediated phosphorylation which inhibited Caco- 2 cell permeability, PLC activation also induced $\mathrm{IP}_{3}$ mediated release of intracellular $\mathrm{Ca}^{2+}$ which increased paracellular permeability. Therefore, in essence, PLC activation can lead to two opposing effects whereby PKC mediated phosphorylation reduces cell permeability, and increased intracellular $\mathrm{Ca}^{2+}$ concentrations would increase tight junction permeability. However, the full nature of the effects of PKC activation on tight junction permeability are complex; PKC activation can up- or downregulate tight junction permeability depending on the individual isomers, differences between cell types, and experimental conditions. ${ }^{22}{ }^{23}$ Nevertheless, we have presented interesting data which showed that a single isomer of LA had the ability to affect the distribution of occludin in Caco-2 cells which in turn was associated with increased paracellular permeability. Further research is required to examine the full nature and molecular basis of this effect of the trans-10 isomer of CLA.

1 Ip C. Review of the effects of trans fatty acids, oleic acid, n-3 polyunsaturated fatty acids, and conjugated linoleic acid on mammary carcinogenesis in animals. Am f Clin Nutr 1997;66:1523-9S.

2 Lin H, Boylston TD, Chang MJ, et al. Survey of the conjugated linoleic acid content of dairy products. F Dairy Sci 995; 78:2358-65.

3 Chew BP, Wong TS, Shultz TD, et al. Effects of conjugated dienoic derivatives of linoleic acid and $\beta$-carotene in modulating lymphocyte and macrophage function. Anticancer Res 1997;17:1099-106.

4 Turek JJ, Li Y, Schoenlein IA, et al. Modulation of macrophage cytokine production by conjugated linoleic acids in influenced by the dietary $n-6: n-3$ fatty acid ratio. $\mathcal{F}$ Nutr Biochem 1998;9:258-66.

5 Visconneau S, Cesano A, Tepper SA, et al. Conjugated linoleic acid suppresses the growth of human breast adenocarcinoma cells in SCID mice. Anticancer Res 1997;17:96973.

6 Lee KN, Kritchevsky D, Pariza MW. Conjugated linoleic acid and atherosclerosis in rabbits. Atherosclerosis 1994;108: $19-25$.

7 Nicolosi RJ, Rogers EJ, Kritchevsky D, et al. Dietary conjugated linoleic acid reduces plasma lipoproteins and early aortic atherosclerosis in hypercholesterolaemic hamsters. Artery 1997;22:266-77.

8 Hirase T, Staddon JM, Saitou M, et al. Occludin as a possible determinant of tight junction permeability in endotheble determinant of tight junction perm
lial cells. F Cell Sci 1997;110:1603-13.

lial cells. F Cell Sci 1997;110:1603-13.
9 Anderson JM, Van Itallie CM. Tight junctions and the Anderson JM, Van Itallie CM. Tight junctions and the
molecular basis for regulation of paracellular permeability. Am f Physiol 1995;269:G467-75.

10 Sakakibara A, Furuse M, Saito M, et al. Possible involvement of phosphorylation of occludin in tight junction formation. $\mathcal{F}$ Cell Biol 1997;137:1490-5.

11 Wong V. Phosphorylation of occludin correlates with occludin localization and function at the tight junction. Am $\mathcal{F}$ Physiol 1997;273:C1859-67.

12 Balda MS, Matter K. Tight junctions. F Cell Sci 1998;111: 541-7.

13 Furuse $\mathrm{M}$, Itoh $\mathrm{M}$, Hirase $\mathrm{T}$, et al. Direct association between occludin and ZO-1 and its possible involvement in the localisation of occludin at tight junctions. F Cell Biol 1994;127:1617-26.

14 Anderson JM, Balda MS, Fanning AS. The structure and regulation of tight junctions. Curr Opin Cell Biol 1993;5: regulation $772-8$.

15 Kim SK. Tight junctions, membrane-associated guanylate kinases and cell signalling. Curr Opin Cell Biol 1995;7:6419.

16 Balda MS, Whitney JA, Flores C, et al. Functional dissociation of paracellular permeability and transepithelial electrical resistance and disruption of the apical-basolateral intramembrane diffusion barrier by expression of a mutant tight junction membrane protein. F Cell Biol 1996;134: 1031-49.

17 Jiang WG, Bryce RP, Horribin DF, et al. Regulation of tight junction permeability and occludin expression by polyunsaturated fatty acids. Biochem Biophys Res Comm 1998;244: 414-20.

18 Pinto M, Robine-Leon S, Appay M-D, et al. Enterocyte-like differentiation and polarisation of the human colon carcinoma cell line Caco-2 in culture. Biol Cell 1983;47: carcinom

19 Rubas W, Cromwell ME, Mrsny RJ, et al. An integrated mubas W, Cromwell ME, Mrsny RJ, et al. An integrated
method to determine epithelial transport and bioactivity of method to determine epithelial transport and bioactivity
oral drug candidates in vitro. Pharm Res 1996;1:23-6.

20 Parkos C, Coglan S, Delp C, et al. Neutrophil migration accross a cultured epithelial monolayer elicits a biphasic resistance response representing sequential effects of transcellular and paracellular pathways. f Cell Biol 1992;117: $757-64$

21 Lindmark T, Kimura Y, Artursson P. Absorption enhancement through intracellular regulation of tight junction permeability by medium chain fatty acids in Caco- 2 cells. $\mathcal{F}$ Pharm Exp Ther 1998;284:362-9.

22 Balda MS, Gonzales-Mariscal L, Matter K, et al. Assembly of the tight junction: The role of diacylglycerol. 7 Cell Biol 1993;123:293-302.

23 Stuart RO, Nigam SK. Regulated assembly of tight junctions by protein kinase C. Proc Natl Acad Sci USA 1995;92:6072-6. 